\title{
PESCA ARTESANAL: seu significado cultural ${ }^{1}$
}

\author{
PESCA ARTESANAL: su significado cultural
}

\section{HANDMADE FISHING: its cultural meaning}

\author{
Anelino Francisco da silva \\ Universidade Federal do Rio Grande do Norte \\ Rua teatrólogo Meira Pires, 2357, apto. 1202. Capim Macio. Cep. 59080090. \\ Natal-Rio grande do Norte \\ aikosnelus@ufrnet.br
}

\section{Resumo}

A pesca artesanal no seu significado cultural trata das relações socioculturais e econômica, que se caracteriza no espaço e no tempo, como um objeto de estudo de complexidade e de significado. Sua importância dá-se por meio da prática exercida pelos pescadores no seu cotidiano terra/oceano. O pescador na luta pela sua sobrevivência constrói sua vivência sociocultural e identitária, adquirida cotidianamente pela tradição e pela cultura. A pesca em sua dinâmica espacial e em suas relações estabelece por meio da representação e dos significados específicos, que enquanto atividade socioeconômica é forjadora de uma construção imagética ímpar.

Palavras-chave: Pesca; Atividade pesqueira; tradição; cultura; identidade.

\section{Resumen}

La pesca artesanal en su significado cultural trata de las relaciones socioculturales y económicas, que se caracteriza en el espacio y en el tiempo, como un objeto de estudio de complejidad y de significado. Su importancia se logra por medio de la práctica ejercida por los pescadores en su cotidiano tierra/océano. El pescador en la lucha por su supervivencia, construye su vivencia sociocultural y de identidad, obtenida cotidianamente por la tradición y por la cultura. La pesca en su dinámica espacial y en sus relaciones establece por medio de la representación y de los significados específicos, que mientras actividad socioeconómica es forjadora de una construcción de imágenes impares.

Palabras Clave: Pesca; Actividad pesquera; tradición; cultura; identidad 


\section{Abstract}

The handmade fishing in its cultural meaning deals with the sociocultural relationships that have been described in time and space as an object of complexity. And meanings its importance occures around the practice done by the fishmen in their everday life, land/ocean and ocean/land.The fishman in his survival fight, builds his sociolcultural abd identity existence acquired every single day for the tradition and culture.The fishing in its spatial dynamic and relations estabilish by the represantion abd the specific meanings meanwhile the socioeconomic activity is the harger of an odd building.

Key-words: fishing, fishing activity, tradition, culture, indentity.

\section{Introdução}

Ao fazer a colheita nos imensos campos do oceano o pescador começa a criar uma cultura associada a este espaço. Espaço de relações que caracterizam no tempo e no espaço, convivências que resultam dum aparato de significados. Aqui a de se pensar que há entre os homens um limite cultural dado, pelo modo como as crenças e os valores partilhados são resocializados. A cultura da pesca é labiríntica.

\section{A cultura dos pescadores}

Ao se pensar na pesca artesanal, apreende-se que o espaço real do pescador está sempre mudando em sua fisionomia e nas relações sociais. Assim, a cultura dos pescadores artesanais inspira-se no funcionamento da história vivida, dos significados e das representações.

A respeito de "significado", é preciso lembrar que a fixação do termo ${ }^{2}$ para expressar a percepção do objeto em torno de nós configura um mundo possível de realidade que permanecerá sempre irredutível a paradigma de "relação" entre termos constituídos. Do ponto de vista da conduta individual, o significado se caracteriza pela

\footnotetext{
${ }^{1}$ Pesquisa realizada em Pós-doutorado com apoio da CAPES.

2 "Significado" foi resgatado não só nos teóricos, mas também no Dicionário de língua portuguesa contemporânea (2001), esclarece ser "O que uma coisa exprime", significa "ação ou resultado de
} 
disposição de um conjunto de objetos, signos e outras presenças vivas a suscitar em nós comportamentos distintos quanto às significações, que podem exprimir, segundo Franklin Fearing "um padrão de forças dotado de um significado abrangente" (FEARING, 1987, p. 57). Aqui é perceptível a noção de interesse e a recíproca pertença entre o intérprete e aquilo que ele interpreta (GOMES, 1991) ${ }^{3}$, força atribuída pelos elementos de uma experiência, apropriando-se dela pela "significação"(KOSSOVITCH, 1979).

O sentido está, pois, sempre numa relação intrínseca com o próprio sentido, o que sugere que a compreensão não pode ser concebida como fruto de uma relação. Ao contrário, a experiência da interpretação faz ver que os próprios termos de uma relação só se constituem enquanto objetos, recortados, que se caracterizam como um horizonte de sentidos.

Já por "identidade", compreende-se que o conteúdo é a pertença e também que ela define as dimensões das comparações sociais, que (re)alimentam o seu conteúdo. Além disso, incorpora também o conteúdo de normas específicas do grupo. Mesmo atitudes ou comportamentos que não sejam explicitamente reconhecidos como valores do grupo, podem ser fontes relevantes de expressão de identidade, desde que sejam vistos como típicos ou característicos de membros de um grupo particular e guiem as atitudes e comportamentos dos membros desse grupo.

$\mathrm{Na}$ descoberta das coisas, "ser-no-mundo" pode exprimir o conteúdo do patrimônio de idéias que a cultura emite, como valores, representações, procedimentos práticos e formas de dominação, que tornam possível a expressão no domínio simbólico, nas relações entre os homens. Aqui se deve pensar que há entre os homens um limite cultural prévio, dado pelo modo como as crenças e os valores partilhados pelos indivíduos operam no nível da própria percepção sensível, ou pela adoção inconsciente de uma forma histórica de representação como paradigma para a

significar" e/ou "O que uma coisa, um fato representa ou significa", que é significativo "é portador de um sentido".

${ }^{3}$ Gomes, Wilson. Fato e interesses. Textos de Cultura e Comunicação, Revista do Departamento de Comunicação e do Mestrado em Comunicação da Bahia, Salvador, v. 2, n. 26, p. 24-32, jul., 1991. 
compreensão da sensibilidade. Nesse sentido, a "cultura constitui a própria utilidade" (SAHLINS, 1979, p.33).

\section{Trilha cultural/Re-encantamento da vida na pesca}

Portugal e Brasil, países de cultura atlântica, têm na captura de produtos marítimos um modelo cultura artesanal e de trabalho em que os pescadores lançam-se ao oceano/mar em seus barcos de pesca, todas as manhãs e todas as tardes, e ao fim do dia estão de retorno aos seus familiares, efetivando uma situação real e significativa. É o re-encanto, com a vida na pesca; o seu esforço foi compensado. É o pescador que retornou com o produto de sua luta e bravura à terra, à comunidade.

A cultura da pesca é labiríntica em toda a sua práxis, dada sua a construção, a sua significação e o sentido de unidade econômica e política. O fato é que o universo cultural da pesca é uma representação factual da arte de pescar, da construção naval de barcos, da linguagem específica do pescador, do universo imagético dos pescadores, da religiosidade e da história quotidiana dos velhos mestres da pesca. Logo, vê-se que a construção do significado cultural da pesca passa por aquilo a que Graça Capinha alude: a identidade e a cultura, curiosamente, começam a se manifestar no momento em que outra unidade, a econômica e/ou a política, está prestes a ter um fim (CAPINHA, 2000). Através da identidade no território, é possível verificar as marcas do pertencimento e do significado construído na temporalidade pela gente da pesca.

Sesimbra, como Setúbal, exemplos de casos, analisados que nos permitem entender como orienta-se (para) a pesca artesanal mais próxima da costa e para a pesca do alto, tendo como artes de pesca mais utilizada: as redes de emalhar fundeadas, os aparelhos de anzol, os arrastos de vara, as redes cercadoras, as xávegas, as redes de arrasto pelágicas e as redes de arrasto de fundo. Nesse território de pesca, a comunidade sesimbrense, ao longo de sua trajetória geográfico-histórica, constata-se o forte poder de identificação e significação que tem a pesca na vida laborial e cultural da comunidade.

Lembremos que em Homens do mar, Odete Saint-Maurice (2002, p. 31) diz que os pescadores, no seu território, são homens de

músculos de aço! Corpos bronzeados 
Tal qual estátuas fortes,

esculpidas em convulsões de génio,

renascidos na glória de talentos consagrados!

$[\ldots]$

Olhai que belo quadro criar!

As státuas são agora homens do mar!"

Nessa mesma sincronia, em Pescadores, vamos encontrar, nos versos de Afonso Nunes Gomes, o ressaltar de uma significação, ao dizer:

"Ó bravos pescadores de músculos d’aço

$[\ldots]$

fitando o S 'paço azul, Omnipotente

$[\ldots]$

Alheio ao mar e a p 'rigos indif 'rente,

Ampara e remedeia tanta gente

Que tem negra fome o rude traço! (GOMES, 2002, p.49).

António Matias, em "Quadra ao pescador”, numa estrofe magnífica faz do seu reconhecimento uma significação do que é ser pescador e diz:

$[\ldots]$

Não se pode aquilatar

Pescador, teu heroísmo,

Quando lutas sobre o mar

Indiferente ao negro abismo (MATIAS, 2002, p.72).

Numa outra passagem, esse poeta nos diz o que é significativo no pescador:

No vai e vem das feras

Indiferente à tempestade,

Pescador, tu não te apagas,

És o farol da eternidade (MATIAS, 2002, p. 72). 
Essa identificação que a comunidade sesimbrense tem com a pesca é expressa no trabalho dos pescadores e tem na vida e na morte, interlocutoras, quotidiana, dos homens do mar. Afonso Pereira, em Podem crer! diz:

$[\ldots]$

Na triste comédia - a "vida"!

$[\ldots]$

Mas enfim sigo meu fado

Porque estou contratado

Para não faltar um dia.

$[\ldots]$

E todas são com certeza

Actores nestas condições.

Uns fazem de figurões ...

E outros mostram a pobreza!

E só tem fim esta lida

Quando a morte aparece,

Logo então o pano desce...

Termina a comédia [...] a "vida" (PEREIRA, 2002, p.158).

Os poetas e escritores que enaltecem os "homens do mar" fazem uma leitura especial da labuta do pescador, num olhar plural, em que viver e morrer no mar são acontecimentos significativos e representativos. O compositor Dorival Caymim descreve o pescador da Bahia como um forte. O pescador só vive para o mar, embora, quando lá está, o seu desejo seja voltar para a terra. O seu território de poder é o mar, nele se sente forte; mas absolutamente consciente de que o oceano, às vezes, é indomável. Portanto, para aqueles que fazem do oceano o lugar de trabalho, morrer numa de suas idas ao mar é uma certeza. Talvez por isso a leitura faça essa constatação: “É doce morrer no mar, nas ondas verdes do mar” (CAYMMI, 1943) é que na ida para "o mar ... pescador quando sai, nunca sabe se volta, nem sabe se fica" (CAYMMI, 1996).

A geografia do pesca(dor) é construída pelos meios oceano e terra. Meios carregados de simbolismo e representação diferentes, nos quais os pescadores se 
encontram e se complementam, numa busca de sustentação e do acochego social, de um lado; do outro, estão o enfrentamento, a bravura e a sorte, que constituem seu mundo imagético.

Essa geografia espraia-se numa rede espacial consignada através do engendramento do trabalho e da representação cultural, que a pesca tem no seu bojo fisíco. Nessa construção, o povo que nela está age e se manifesta como unidade socioeconômica, mas tendo como essencialidade a identidade, que adquire significação e dá sentido a sua própria construção geocultural. São os territórios da pesca móveis os circuitos da mercadoria, a reprodução dos produtores e os usos do espaço costeiro. Acrescentem-se a tudo isso os aspectos culturais das comunidades pesqueiras, que se expressam na religiosidade e na manutenção dos signos tradicionais, característicos de comunidades pesqueiras.

Essa geografia espraia-se numa rede espacial consignada através do engendramento do trabalho e da representação cultural, que a pesca tem no seu bojo fisíco. Nessa construção, o povo que nela está age e se manifesta como unidade socioeconômica, mas tendo como essencialidade a identidade, que adquire significação e dá sentido a sua própria construção geocultural. São os territórios da pesca móveis os circuitos da mercadoria, a reprodução dos produtores e os usos do espaço costeiro.

Acrescentem-se a tudo isso os aspectos culturais das comunidades pesqueiras, que se expressam na religiosidade e na manutenção dos signos tradicionais, característicos de comunidades pesqueiras.

A geografia de que se está a falar é elaborada por comunidades pesqueiras, algumas dessas alicerçadas também por outras economias: a industrial e a de serviço, no caso o turismo. Contudo, cada uma delas apresenta suas peculiaridades.

\section{Lota e Colônia de pescadores: ação e prática}

As formas de organização da atividade pesqueira revelam uma temporalidade grande e uma espacialização da pesca em dois meios: o oceano e a terra. No oceano uma "espacialização do ato produtivo em si e em terra a geografia dos circuitos da mercadoria, a reprodução dos produtores e os usos do espaço costeiro" (CARDOSO, 1999, p. 93). 
O fato de a pesca basear-se na captura de recursos não totalmente controlado, não permite que a racionalidade capitalista se imponha no setor da produção. E aí entram as infra-estruturas designadas por "lotas" (Portugal) e "colônias de pescadores" (Brasil). As lotas têm por objetivo maior o controle da produção pesqueira, executandose também a ação da venda do produto entregue pelos associados, que, após comercializado, no prazo de até quinze dias é pago aos pescadores. Quanto às colônias de pescadores, funcionam, essencialmente, como associações dos pescadores: não atuam no controle e gestão da produção. Como entidades atuam no cadastramento dos pescadores e pescadoras, orientando-os na questão da segurança social.

Pode-se mensurar que as duas entidades - lota e colônia de pescadores - têm uma representação carregada de grande significado, nas comunidades de pesca. Significam segurança social para o pescador. Para ele, o importante é poder pescar e, ao chegar da maré, entregar a produção capturada à lota e não ter nenhuma preocupação com a venda do produto. É ela que vai agir na comercialização, em função da oferta e da procura; esse tipo de serviço não é prestado pelas colônias de pescadores, visto que o governo brasileiro através do ministério da pesca, ainda não assimilou a dimensão social, que tal aparato estabelece. Além disso, os que possuem autorização e contribuem segundo as normas da entidade, garantem a sua segurança social, visto que, na atividade pesqueira, a longevidade do homem do mar é baixa. Portanto, a contribuição dá-se em função das quotas. Logo não havendo "fuga" do produto, as participações serão maiores, o que será compensatório. Porém na atividade está sempre a ocorrer incompreensões, por falta de conscientização dos

velhos pescadores, que são levados pelas conversas dos camaradas, gerando conflitos internos.

Quer seja em Portugal, quer no Brasil, os pescadores sempre estão a reclamar de suas instituições, principalmente quando chegam à fase de não mais poder ir pescar e em caso de doenças provocadas pela atividade. Entretanto a lota e as colônias de pescadores no seu universo têm significados expressivos, do ponto de vista administrativo e do ponto de vista cultural, que podem ser captados no texto A lota, de Emília Mendes, poetisa sesimbrense: 
Estão na praia os compradores,

quem o peixe comprar!

da lenga-lenga, os valores

Vão breve chui arrancar!

\begin{abstract}
Numa algazarra incontida
há pescadores, vendedores,

carros, carroças. É a lida

duma vida e seus valores!
\end{abstract}

Correm, uns querem comprar,
outros apenas ouvir
e lá vai chui esperar
o lote que vai seguir!(MENDES, 2002, p. 105).

A dinâmica e a relação atuam na construção do espaço da produção pesqueira. A reprodução das espécies, as migrações, os ambientes ecológicos onde a pesca se realiza, a influência dos ciclos naturais, sejam eles do ar, do mar ou das espécies, atuam diretamente na construção desse espaço. Por sua vez, as distintas formas de organização da produção também estabelecem uma espacialização na pesca. O processo de exploração (captura) sobre algumas espécies tem levado à destruição de estoques, agravando a situação do setor. Nessa direção, as estatísticas de pesca têm diagnosticado que a cada ano, a captura de pescado tem diminuído, tanto em Portugal como no Brasil.

Nesse sentido, as colônias de pescadores têm atuado junto aos pescadores, associados ou não, ensinando-lhes uma cultura de explorar os recursos naturais do mar e dos rios, preservando-os. Embora as colônias de pescadores, no universo das comunidades pesqueiras, não satisfaçam a "gregos e troianos", elas têm respaldo e reconhecimento inclusive, daqueles que se opõem à sua atuação.

Certamente, a "reversibilidade generalizada" do significado da produção e do consumo está a transformar-se numa prática cultural, mediante "a qual os significados, os símbolos, os códigos e as relações sociais são permanentemente reproduzidas “(CACHINHO, 2000, p. 61).

Com isso, confere-se às lotas e às colônias de pescadores a sua importância e representação no "mundo" da pesca artesanal. Nos códigos a elas atribuídos o 
desempenho passa pela mudança social, que se ancora num princípio fundamental: a representação simbólica ou o imaginário social que liga os seres humanos ao mundo em que vivem, de olho no mundo globalizado ${ }^{4}$.

\section{A natureza da pesca - um jogo de imagens}

A relação sociedade-natureza é sempre uma relação cultural, pois envolve hábitos e práticas situados em uma escala de valores. O valor da pesca (artesanal) para a sociedade está diretamente ligado ao contexto histórico, político e social.

Nesse sentido, a cultura e a identidade dos pescadores portugueses e brasileiros do oceano/mar, de rios e dos estuários têm alicerce na convivência quotidiana, a partir do que se estrutura um modo de vida e o sistema de valores e referências próprios. Pode-se constatar que as políticas de desenvolvimento interferiram diretamente na cultura das populações pesqueiras, alterando as formas de lidar com os ecossistemas, devido às mudanças na dinâmica física e econômica. Desse modo, a natureza passa a estar atrelada a - cultura capitalista -, que vai gerando conflitos pela garantia das formas de atuação.

No oceano/mar, os territórios são mais que espaços delimitados. São lugares conhecidos, nomeados, usados e defendidos. A familiaridade de cada grupo de pescadores numa dessas áreas, marítima ou não, cria territórios que são incorporados à sua tradição (MALDONALDO, 1993). Isso permite entender que a identidade é um complexo em que as " subjetividades individuais e coletivas" (WASSERMAN, 2001) são as matérias-primas para a compreensão da identidade.

As comunidades pesqueiras possuem natureza específica, que tende a imprimir imagens culturais, peculiares a cada espaço geográfico em que a atividade pesqueira se desenvolve, definindo uma cartografia sociocultural, repleta de signos.

A imagem da pesca está carregada de simbologias que representam o estado atual da atividade nos territórios português e brasileiro. Essa leitura consubstancia-se a partir da gestão da pesca, pelo processo de desmonte por que passa o setor e pela apatia do Estado, perante a crise vivenciada, que se alastra desde meados de 1980. Com essa situação, a pesca não consegue atrair novos contingentes de pescadores.

${ }^{4}$ Herculano Cachinho discute mudança social e o imaginário pós-moderno. 
No Brasil, por exemplo, a pesca artesanal apresenta peculiaridade regional, tanto em relação à produção quanto às tendências. Há regiões onde a pesca é predominantemente artesanal, com baixa tecnologia, enquanto em outras, como a Sudeste e a Sul, existe uma pesca artesanal e uma de cunho industrial forte: no Rio de Janeiro, em Santa Catarina e no Espírito Santo. A região Nordeste, nos últimos anos, tem introduzido tecnologias significativas, graças ao arrendamento de barcos estrangeiros por indústrias pesqueiras nordestinas. Entretanto, nas comunidades pesqueiras, não há ninguém que pesque e tenha um filho, que queira que ele venha para o mar, é um desencanto geral. Por outro lado, a riqueza faunística marinha da costa brasileira nem sempre deixa à mostra que a pesca sempre teve que se adaptar à baixa produtividade pesqueira, determinada por fenômenos naturais.

Essa tendência também é verificada no setor pesqueiro de Portugal, em que as estatísticas da pesca têm diagnosticado a queda da produção capturada. Embora o Estado tenha feito grandes investimentos, por exemplo na formação de profissionais da pesca, mas os jovens estão de costas para uma atividade arriscada, mal paga e sem horários de trabalho Dir-se-ia que a vida no mar, pela sua dureza e pelas suas peculiaridades, deve oferecer melhores condições remuneratórias para poder atrair os jovens pescadores. Os números da Escola de Pesca e da Marinha de Comércio indicam que havia 40 mil marítimos matriculados em barcos de pesca em 1990 e 20 mil em 2003. A redução dos embarcadiços foi acompanhada por uma diminuição das embarcações: dos 16 mil de 1990 restavam cerca de 10 mil em 2004, e 80\% delas dedicadas à pesca artesanal (BARBOSA, 2006).

A distribuição geográfica de captura do pescado em Portugal, de acordo com a divisão marítima, pode ser, assim, cartografada em três zonas: norte, centro e sul. No norte, a atividade pesqueira é intensa, apresentando infra-estrutura de portos abrigos e uma frota barcos com poder tecnológico de captura, portanto mais dinamizada; no centro a atividade pesqueira se diferencia pela arte de pesca, pelas espécies capturadas, sendo essencialmente uma pesca artesanal e destacando-se Sesimbra, Nazaré e Póvoa do Varzim. É pertinente colocar que a ação política de algumas comunidades locais, engendrou situações que fizeram com que elas conseguissem infra-estrutura de portos como ocorreu, por exemplo, nas três acima citadas. 
A situação da pesca está expressa na performance dos pescadores. São eles que imprimem o aspecto cultural, às diversas comunidades pesqueiras, daí por que o cenário e a imagem ${ }^{5}$ fazem compreender a cultura codificada pela prática dos pescadores e perceber a dinâmica do processo de identificação do pescador com a comunidade e a significação de tal processo, nesse momento de identificações, em que cada um serve ao outro de espelho,

quer para afirmar a sua superioridade, quer para confirmar a inferioridade do outro, assim, forjando a cultura e a identidade de cada um.

As comunidades pesqueiras foram sempre olhadas como comunidades relativamente marginais e a cultura dominante foi sempre a rural. Que fizeram os pescadores? Eles inverteram essa situação e a tudo em que a cultura dominante via algo de negativo, atribuíram valor positivo. Isso é especialmente nítido no papel desempenhado pelas mulheres: ao contrário da mulher do agricultor, a do pescador ela ordena a gestão do patrimônio do casal e as relações com as instituições.

Do ponto de vista cultural, do uso e ocupação, a zona costeira do Brasil caracteriza-se por um cenário em que ocorre a captura de produtos do mar, via políticas de incentivos fiscais que favorecem a instalação de indústria e processamento de pescado, enquanto as ações da gestão governamental para a exploração artesanal, realizada pelos pescadores e pescadoras, são incipientes e contraditórias. Entretanto a atividade pesqueira artesanal tem respondido diferentemente a essa situação.

Nesse sentido, os desembarques da pesca artesanal são responsáveis por 52,5\% da produção do pescado capturado no país (VASCONCELLOS et al., 2004), o que desmistifica a máxima de que os pescadores artesanais são ineficientes e improdutivos. Também tem se caracterizado um outro processo: em muitos estados a urbanização dos pescadores artesanais implica o deslocamento para as periferias das cidades costeiras. Essa situação tem sido causada pelo aumento do turismo e a especulação imobiliária. Entretanto, no estado do Paraná, em cerca de 60 vilas de pescadores, rurais e urbanas, no interior das baías e na frente oceânica, existe dispersão, mas os pescadores estão concentrados no bairro ou na vizinhança, onde nem toda a população é de pescadores (ANDRIGUETTO FILHO, 1999).

\footnotetext{
${ }^{5}$ Ler JOLY, Martine. A imagem e os signos. Lisboa: Edições 70, 2005.
} 
A conseqüência é percebida nas praias costeiras, onde as comunidades pesqueiras estão deixando de exercer, plenamente, a atividade de pesca, nos espaços onde outrora praticavam as fainas complementares. A beira-mar mingua, fisicamente e culturalmente, para o uso dos pescadores, esvaziando-se seu significado. Pontua-se que tal espaço é área da União onde eram construídas pelos pescadores as caiçaras para guardar os apetrechos da

pesca e onde eles "trocavam prosas" com os camaradas e com quem lá aparecesse. Agora está apropriada pela rede de hotelaria e pelos barraqueiros, em nome do turismo.

Com o distanciamento das áreas de habitação dos pescadores, aumentou a dificuldade de participação da mulher na faina da pesca. Quando residiam próximo ao mar/oceano, elas desempenhavam importante papel na atividade, pela facilidade de locomoção espacial. Porém sua participação é efetiva - elas pescam, controlam o dinheiro ganho com as pescarias; nas lotas, são elas quase quem vai receber o pagamento. Dessa forma, as mulheres constroem uma nova relação na comunidade.

Não obstante a diversidade cultural, os relatos dão conta de muita semelhança na situação da mulher na pesca artesanal das diversas regiões. No Brasil, essencialmente no Pará, cabe às mulheres tecer redes, beneficiar o pescado, pescar próximo à terra, capturar caranguejos e moluscos nos manguezais. Em Santa Catarina, a participação da mulher nesse setor só se dá no "lanço da tainha", quando a sua atuação é considerada fundamental. Em Pernambuco, nas comunidades em que a pesca artesanal é a atividade básica da economia local, as mulheres pescadoras atuam em pescarias de estuários e rios, na captura de marisco e sururu (crustáceos) e como vendedoras de peixes e crustáceos, tanto na comunidade, como em feira-livre, por exemplo, na cidade de Goiana (SILVA, 1998). No Rio Grande do Norte, a participação da mulher se dá na preparação do peixe para a secagem, como pescadora e ou marisqueira e no conserto de redes. Ana Franco (2004) faz o regaste da trabalhadora da pesca de Antonina (Paraná), dizendo que lá as mulheres estão presentes de diversas maneiras e, em grande parte dos casos, elas possuem um papel ativo, exercendo diversas funções dentro da cadeia produtiva e também servindo de suporte para a reprodução familiar das comunidades pesqueiras. 
Em princípio nas comunidades pesqueiras interiorizadas, a pesca é ainda importante atividade econômica, que as mulheres exercem lado a lado com os camaradas, impondo nova ordem no trabalho e culturalmente redefinindo os papéis.

Portanto o trabalho das mulheres nas comunidades pesqueiras assume função importante: centenas de famílias dependem da renda do trabalho dessas trabalhadoras.

A mulher pescadora sempre desempenhou função primordial para a manutenção doméstica, porque a faina a ela destinada, se a ela não lhe coubesse, a outrem seria delegada, e o pagamento por tais tarefas teria outro direcionamento. Da forma como ocorre, o dinheiro (ganho, mas não recebido, portanto invisível) entra na renda do pescador. Ora, deduzidos os rendimentos que se pagaria a outro trabalhador, a renda do companheiro/pescador baixaria. Portanto, deduz-se que o resultado do trabalho da mulher na faina da pesca acrescido ao do companheiro/camarada, eleva a renda e dá para prover o sustento familiar.

\section{Artes de pesca - tradição e cultura}

O domínio das pescas tem o significado de que as atividades humanas são indissociáveis do espaço em que se produzem. A paisagem geográfica das regiões costeiras prediz um complexo de interações entre os muitos grupos sociais que, direta ou indiretamente, a utiliza. Contrastes e diferenças significativos da paisagem podem constituir objeto de reflexão sobre a incomensurabilidade do oceano e a necessidade de sobrevivência.

Por isso o mar/oceano é um referente de poder na vida daqueles que o exploram e como tal apresenta-se por um espectro de

\footnotetext{
emoções antitéticas peculiares, de amor e ódio, segurança e temor, evocando simultaneamente o desconhecido, a transcendência, a regularidade cíclica e a imprevisibilidade; seara e cemitério - poder de vida e morte, portanto, e daí uma certa coloração trágica e fatalista na fé religiosa e nos discursos que os marítimos produzem sobre si próprios e sobre o mundo que os rodeia impelidos pela vertigem da escassez ou da abundância de peixe e confrontados, sempre, com a aleatoriedade intrínseca às técnicas de captação dos recursos de que dependem para a sobrevivência (NUNES, 2001, p. 35).
}

Pois no trabalho de pescar é valiosa a ação do homem sobre a natureza oceânica, que pode corresponder ao enfrentamento da ação mística do oceano. 
No universo da pesca, é notória a significação das artes de pesca e do engenho que elas são como ferramentas de trabalho. Em algumas situações também a própria embarcação é indissociável do engenho, como no caso da arte xávega, por exemplo (BRITO, 1994, p, 198).

As artes de pesca são todos os instrumentos ou métodos que permitem a captura de peixe, molusco ou crustáceo. Esses instrumentos ou métodos de trabalho da pesca são referências e estão carregados de significados - econômico, cultural e artístico - que, na história vivida das comunidades pesqueiras, marcam e tipificam os espaços da pesca.

O cruzamento de significados que se constroem do estado das artes de pesca traduz a perspectiva cultural e a forma como foram forjadas as imagens, essencialmente pela utilização da arte.

As artes de pesca agregam as "artes passivas e artes ativas" (AMORIM, 2001, p.231). As passivas são aquelas postas à espera dos peixes, que se dirigem, voluntariamente, para as armadilhas - as redes de emalhar, os anzóis -, enquanto, as artes ativas o pescador/a pescadora dirige ao encontro dos peixes, a fim de capturá-los, o que implica a detecção dos cardumes, para serem apreendidos pelas redes de arrasto (BRITO, 1994).

As artes de pesca acima listadas representam o processo do exercício de captura realizado pelos pescadores e pescadoras no território de pesca - o oceano/mar. Essas artes de pesca, pelas suas especificidades, vão atender demandas pesqueiras, as quais, indissociavelmente, se atrelam a geomorfologia do fundo oceânico, às espécies a serem capturadas, à conjugação da confecção do utensílio com a matéria-prima ideal à preparação da arte e o manuseio dos trabalhadores/pescadores. Tais fatores terminam por caracterizar os aspectos socioculturais do trabalho da pesca.

\section{Considerações finais}

A situação da pesca está expressa na performance dos pescadores. São eles que imprimem o aspecto cultural às diversas comunidades pesqueiras, daí por que o cenário e a imagem ${ }^{6}$ fazem compreender a cultura codificada pela prática dos pescadores,

\footnotetext{
${ }^{6}$ Ler JOLY, Martine. A imagem e os signos. Lisboa: Edições 70, 2005.
} 
perceber a dinâmica do processo de identificação do pescador com a comunidade e a significação de tal processo, nesse momento de identificações, em que cada um serve ao outro de espelho, quer para afirmar a sua superioridade, quer para confirmar a inferioridade do outro, assim, forjando a cultura e a identidade de cada um.

Quer seja em Portugal, quer no Brasil, os pescadores sempre estão a reclamar de suas instituições, principalmente quando chegam à fase de não mais poder ir pescar e em caso de doenças provocadas pela atividade. Entretanto a lota e as colônias de pescadores no tempo e no espaço têm significados expressivos, do ponto de vista administrativo e do ponto de vista cultural.

\section{Referências Bibliográficas}

ACADEMIA DAS CIÊNCIAS DE LISBOA. O Dicionário de língua portuguesa contemporânea. Braga: Tilgráfica S.A., v.2, 2001.

ANDRIGUETTO FILHO, José Milton. Sistemas técnicos de pesca e suas dinâmicas de transformação no litoral do estado do Paraná, Brasil. Tese de Doutorado. Université de Bordeux II. Paris, 1999.

AMORIM, INÊS. História do trabalho e das ocupações. As pescas. Oeiras: Celta Editora, 2001.

BARBOSA, Paulo Jorge. Não há novos pescadores. Pública, Encarte Jornal Público, Lisboa, 05 março, 2006, p.51-53.

BRITO, Raquel Soeiro. Portugal, perfil geográfico. Lisboa: Estampa, 1994.

BROGGER, Jan. Pescadores e pés-calçados. Nazaré: Impressora econômica, 1992

CACHINHO, Herculano. Identidades, consumo e mudança social. Arquivo de Beja, Beja, Actas III Jornadas, Congresso, tomo 1, p. 61-66, 2000. 
CAPINHA, Graça. A poesia dos emigrantes portugueses no Brasil: ficções críveis no campo da(s) identidade(s). In: FELDMAN-BIANCO, Bela et al. Identidades. Estudo de cultura e poder. São Paulo: Editora Hucitec, 2000, p.107-149.

CARDOSO, Eduardo Schiavone. Geografia e pesca: contribuições para uma análise de conjunto. Boletim Paulista de Geografia. São Paulo, n. 76, dez., p. 85-100, 1999.

FRANCO, Ana Cristina. Caracterização da comunidade pesqueira de Antonina, Paraná. Monografia. UFPR, 2004.

GOMES, Afonso N. Pescadores. In: RAPAZ, António Cagica, MARQUES, António R., PÍTÔRA, Paulo e MARTINS, Pedro (org.) Os Chamadores-cancioneiro de sesimbra. Sesimbra: Câmara municipal de Sesimbra, v.1, 2002, p.49

KOSSOVITCH, Leon. Signos e poderes em Nietzsche. São Paulo: Editora Ática, 1979.

JOLY, Martine. A imagem e os signos. Lisboa: Edições 70, 2005.

MALDONALDO, S. C. Mestres e ares: espaço e indivisão na pesca marítima. São Paulo: Anablume, 1993.

MATIAS, António. Quadra ao pescador. In: RAPAZ, António Cagica, MARQUES, António R., PÍTÔRA, Paulo e MARTINS, Pedro (org.) Os chamadores-cancioneiro de Sesimbra. Sesimbra: Câmara municipal de Sesimbra, v.1, 2002. p. 72

MENDES, Emília. Lota. In: RAPAZ, António Cagica, MARQUES, António R., PÍTÔRA, Paulo e MARTINS, Pedro (org.) Os chamadores-cancioneiro de Sesimbra. Sesimbra: Câmara municipal de Sesimbra, v.1, 2002.p. 105.

PEREIRA, Macedo. Podem crer! In: RAPAZ, António Cagica, MARQUES, António R., PÍTÔRA, Paulo e MARTINS, Pedro (org.) Os chamadores-cancioneiro de Sesimbra. Sesimbra: Câmara municipal de Sesimbra, v.1, 2002, p.158. 
SAHLINS, Marshal. Cultura e razão prática. Trad. Sérgio T. Niemeyer Lamarão. Rio de Janeiro:Zahar Editora, 1979.

SAINT-MAURICE. Odete. In: RAPAZ, António Cagica, MARQUES, António R., PÍTÔRA, Paulo e MARTINS, Pedro (org.) Os chamadores-cancioneiro de Sesimbra. Sesimbra: Câmara municipal de Sesimbra, v.1, 2002.

SILVA, Anelino Francisco da. O homem e pesca no estuário do rio Goiana, Pernambuco. Revista de Geografia, Recife, 1998, n. 1, v. 12, p 52-62.

VASCONCELLOS, Marcelo; DIEGUES, António Carlos; SALLES, Renato Rivaden de. Relatório integrado: diagnóstico da pesca artesanal no Brasil como subsídio para o fortalecimento institucional da secretaria especial de Aquicultura e pesca. PNUD/SEAP, versão preliminar, 2004.

WASSERMAN, Claúdia. Identidade: conceito, teoria e história. Agora, Santa Cruz do Sul, v.7, n. 2, p. 7-19, ju./dez., 2001.

Recebido para publicação em maio de 2008 Aprovado para publicação em outubro de 2008 